\section{Spring Books}

\section{Gel Electrophoresis of Proteins: a practical approach}

Edited by D. Rickwood and B. Hames A laboratory aid for all those wishing to separate proteins by gel electrophoresis. Contains detailed recipes and step-by-step instructions on the procedures involved in all the different types of electrophoretic separation.

0904147223 (soft) $£ 7.50 /$ US $\$ 18.00$ 300 pp (approx.)

\section{Rapid and Automated Methods in Microbiology and Immunology:}

a bibliography 1976-1980

A unique reference tool to help you find the simplest method or technique best-suited for your laboratory. Contains over 3000 citations on practically all the rapid and automated techniques introduced in the field during the last five years.

0904147193 (soft) $£ 15.00 /$ US $\$ 36.00$ 200 pp (approx.)

\section{Tooth Surface Interactions and Preventive Dentistry \\ Edited by G. Rolla, T. Sonju and G. Embery \\ Proceedings of a workshop held December 1980 in Oslo and part of a series devoted to current aspects of dental research concerned with the interactions occurring at the tooth surface. Particular emphasis is directed at the role of inorganic ions, especially stannous fluoride, in influencing the metabolism of oral bacteria and their adherence properties. \\ 0904147290 (soft) \\ £15.00/US $\$ 36.00217 \mathrm{pp}, 40$ illus.}

\section{Immunology of the Eye} Proceedings of three workshops sponsored by the National Eye Institute, USA

Workshop I: Immunogenetics and Transplantation Immunity 0904147258 (sott) 乏10.00/US $\$ 25.00300 \mathrm{pp}$

Workshop It: Autoimmune Phenomena and Ocular Disorders 0917000072 (soft)

$£ 10.00 /$ US $\$ 25.00200$ pp (approx.)

Workshop III: Infection, Inflammation and Allergy 0917000080 (soft) £10.00/US $\$ 25.00300$ pp (approx.)

Prepaid orders and requests for further details to:

Information Retrieval 1 Abbey Street, Eynsham, Oxford OX8 1JJ, England 1911 Jefferson Davis Highway, Arlington, VA 22202, USA

\title{
Colourful tale of two Voyagers
}

J. Veverka

Voyage to Jupiter. By David Morrison and Jane Samz. Pp.199. (National Aeronautics and Space Administration: 1980.) Pbk $\$ 7.50$ US only.

NASA-sponsored books describing flight missions to various planets are not hard to find. Unfortunately, good ones are as scarce as impact craters on the surface of Io. Typically, such books amount to little more than collections of pictures intermingled with spacecraft details and other mission minutiae. Science gets mentioned only in passing and at so superficial a level that even the casual reader feels shortchanged

Voyage to Jupiter is not such a book. It is a beautifully illustrated, vivid account of the two historic Voyager encounters with Jupiter in 1979, as well as a factual summary of the initial scientific results. Everyone should find it interesting; even the sophisticated reader will find it informative.

In part, the successful outcome may result from the combination of talents of the two authors: $\operatorname{Sam} z$, a science writer, and Morrison, a planetary scientist and a member of the Voyager Imaging Team who was personally involved in many of the discoveries described in this book. Certainly, this volume does contain details of the spacecraft construction, the mission profile and the requisite pictures of the major participants, but interwoven with all this is real, substantial science. Voyager's many discoveries - rings, volcanoes, lightning, new satellites and so on - are not merely catalogued chronologically, but are tied into a comprehensive new picture of Jupiter and its satellites. Without question, Voyage to Jupiter is more than a NASA picture book, but it is certainly that too. The Voyagers are the first planetary spacecraft to have sent back large quantities of true colour data, and it would be difficult to imagine a better subject for colour imaging than the jovian system. Many of the best of these pictures are reproduced admirably in this volume.

The book opens with a pair of chapters summarizing our pre-Voyager knowledge of the Jupiter system based on three centuries of telescopic observations and the initial reconnaissance by Pioneers 10 and 11 in 1973-1974. Next, the authors discuss the spacecraft, the scientific work that its eleven instruments were designed to carry out and some of the individuals responsible for these experiments. Then come three chapters giving a day-by-day account of the two encounters. Here the reader can share some of the excitement experienced by those who were fortunate enough to be in Pasadena during these two historic events when major discoveries were being made almost hourly. Two of the remaining three chapters aptly summarize our current, post-Voyager, view of the planet and its satellites, and the volume ends with a discussion of future missions to Jupiter. Sadly, this chapter must be very short. At present, the only mission planned is NASA's Project Galileo, which will investigate the jovian system in the latter half of this decade. For a while at least, our view of Jupiter and its satellites will remain that relayed to us by Voyager in 1979.

Voyage to Jupiter - an excellent little book - sets a high standard for future NASA publications of this sort. In these days of $\$ 30-\$ 40$ science books, it is an absolute bargain which I heartily recommend.

$J$. Veverka is at the Laboratory for Planetary Studies, Cornell University, New York.

\section{Here comes Halley}

\section{David W. Hughes}

The Comet is Coming! The Feverish Legacy of $\mathrm{Mr}$ Halley. By Nigel Calder. Pp.160. ISBN 0-563-17859-0. (BBC: 1980.) f8.75. To be published in the USA by Viking, \$12.95.

"EVERy seventy-six years or so Halley's comet punctuates history like an exclamation mark in the sky". It was last seen in 1910 and it is due back soon. To be precise it will be at perihelion, the point in its orbit closest to the Sun, on 9 February 1986 . The preparation for this momentous event has already started. The European Space Agency is busily organizing the Giotto spacecraft which will pass as close as possible to the cometary nucleus. The International Halley Watch is being supervised by the Jet Propulsion Laboratory in Pasadena and this will co-ordinate all the ground-based and near-space observations of the comet. The public are getting ready 